\title{
DYSPHAGIA
}

\section{The endoscopic evaluation of the oral phase of swallowing (Oral-FEES, O-FEES): a pilot study of the clinical use of a new procedure}

\author{
La valutazione endoscopica della fase orale della deglutizione \\ (Oral-FEES, O-FEES): studio pilota sull'uso clinico di una nuova procedura \\ D. FARNETI 1 , B. FATTORI ${ }^{2}$, L. BASTIAN ${ }^{3}$ \\ ${ }^{1}$ Audiology and Phoniatry Service, Infermi Hospital, Rimini, Italy; ${ }^{2}$ ENT Audiology Phoniatry Unit, University of Pisa, \\ Italy; ${ }^{3}$ Institute of Clinical Physiology, National Council of Research (CNR), Pisa, Italy
}

\section{SUMMARY}

Oral FEES (O-FEES) is an endoscopic procedure conceived to directly visualise the oral phase of swallowing. In the perspective of clinical use, the feasibility, safety and acceptability of O-FEES has been evaluated. Subsequently, the procedure was compared with the radiological gold standard. The acceptability of O-FEES was compared to that of FEES using a 10 point questionnaire submitted to a sample of 52 outpatients complaining of swallowing disorders. Repeated measure analysis of variance (rm-ANOVA) models were used to test the mean difference of acceptability in the same subjects after FEES and O-FEES. Subsequently, another sample of 8 male outpatients underwent a simultaneous O-FEES and videofluoroscopic study (VFSS). The inter-rater reliability using 10 radiological landmarks, compared to O-FEES, was blindly determined between two raters. Inter-rater agreement between the two judges for O-FEES and VFSS scores was assessed with the single score intra-class correlation coefficient (ICC). Differences between FEES and O-FEES answers for each question and among all the items considered overall were statistically significant (rm-ANOVA; F-statistic $\mathrm{p}<0.001)$. The inter-rater agreement concerning endoscopic and radiological evaluations between the two raters showed strong values of intra-class correlation coefficient (ICC) (95\% confidence interval): 0.875 (0.373-0.979) and 0.921 (0.542-0.986), respectively. The Bland-Altman test showed a bias of -0.24 (95\% limits of agreement; -1.77 to +1.19 ), which suggests that both methods produced almost identical results. In clinical practice and compared with FEES, O-FEES is a well tolerated and safe procedure. Compared with the radiological gold standard, O-FEES offers reliable information about oral preparation and oral propulsion of the bolus.

KEY WORDS: Instrumental examination • Endoscopy • Fluoroscopy $\bullet$ FEES • O-FEES • VFSS • MBS

\section{RIASSUNTO}

O-FEES (O-FEES) è una procedura endoscopica, concepita per visualizzare direttamente la fase orale della deglutizione. Nella prospettiva di un utilizzo clinico, la fattibilità, la sicurezza e l'accettabilità dell'O-FEES è stata inizialmente valutata. Successivamente, la procedura è stata confrontata con il gold standard radiologico. L'accettabilità dell'O-FEES è stata confrontata con quello della FEES per mezzo di un questionario a dieci punti, sottoposto ad un campione di 52 pazienti ambulatoriali che lamentavano di disturbi della deglutizione. Il modello Repeated measure analysis of variance (rm-ANOVA) è stato utilizzato per testare la differenza media di accettabilità delle due procedure nello stesso soggetto. Successivamente un altro campione di 8 pazienti ambulatoriali di sesso maschile, è stato sottoposto alla registrazione simultanea di O-FEES e videfluoroscopia (VFSS). L'affidabilità inter-individuale, utilizzando 10 parametri radiologici di riferimento, fra $O$-FEES e VFSS, è stata determinata alla cieca tra due giudici. La concordanza inter-individuale tra i due giudici, per i punteggi di O-FEES e della VFSS è stata determinata con il Single score intra-class correlation coefficient (ICC). Le differenze FEES e O-FEES tra le risposte per ogni domanda e tra tutte le domande considerate, sono risultate statisticamente significative (rm-ANOVA; F-statistica $p<0,001)$. La concordanza inter-individuale fra la valutazione endoscopica e radiologiche tra i due valutatori, ha mostrato una forte correlazione intra-classe (ICC) (intervallo di confidenza al 95\%): 0,875 (0,373-0,979) e 0,921 (0,542-0,986) rispettivamente. Il test di Bland-Altman suggerisce che le due metodiche producono risultati analoghi. Nella pratica clinica e confrontata con la FEES, l'O-FEES è una procedura tollerata e sicura. Rispetto al gold standard radiologico, l'O-FEES offre informazioni affidabili sulla preparazione e propulsione orale del bolo.

PAROLE CHIAVE: Valutazione strumentale $\bullet$ Endoscopia $\bullet$ Fluoroscopia $\bullet$ FEES $\bullet$ O-FEES $\bullet$ VFSS $\bullet$ MBS

Acta Otorhinolaryngol Ital 2017;37:201-206 


\section{Introduction}

The oral phase of swallowing has not yet been assessed by endoscopy ${ }^{12}$ : this seems a limitation of different endoscopic procedures using this tool ${ }^{1-3}$. FEES (Fiberoptic Endoscopic Evaluation of Swallowing) was the first protocol to be proposed ${ }^{1}$. In endoscopy, information about the oral phase of swallowing can be inferred. Base of tongue movements during preparation and propulsion of the bolus and all the events that occur before swallowing can be seen in endoscopy as well as the bolus entering the pharynx and the subsequent motor events before the white-out onset ${ }^{4}$. Moreover, the events that occur after the white-out are better seen in endoscopy. What happens during white-out may be a concern that occurs less frequently compared to the previous conditions ${ }^{5}$, and easily confirmed by residues invading the larynx and the cervical trachea. Paradoxically, the ability of endoscopy to rate false routes seems better than fluoroscopy ${ }^{6}$. Nonetheless, there is agreement that fluoroscopy is ideal for viewing the oral phase of swallowing ${ }^{7}$.

The oral phase of swallowing is a complex miscellany of events: oral preparatory and oral propulsive are the main stages that occur in the oral cavity and their sequence is strictly joined with the other events of the pharyngeal stage of swallowing. The possibility of direct viewing of the oral events allows a better interpretation of the pharyngeal events with a more precise reconstruction of the entire swallowing act. For this reason, to date, VFSS is considered the instrumental gold standard. However, endoscopy offers a direct view of the anatomical features of the pharynx and larynx, and a direct view of their movement characteristics: speed, precision and range. Endoscopy offers an exceptional view of material pooling or bolus residues, and test sensation. Considering these advantages, during endoscopic evaluation the possibility of direct viewing of the oral events might offer a more comprehensive interpretation of the swallowing sequence, similarly to radiological study ${ }^{8}$.

Oral-FEES (O-FEES) is an extension of the FEES procedure conceived to directly observe the oral phase of swallowing ${ }^{8}$. O-FEES offers the clinician a direct view of the oral cavity and its content: in a dynamic perspective, all the events that occur inside the mouth can be seen, except bolus passage through the fauces, due to the white-out.

The aims of this study are to evaluate the: 1) tolerability of O-FEES and 2) inter-rater reliability and concurrent validity by comparing O-FEES with VFSS, limited to predefined radiographical symptoms. The use of O-FEES in clinical practice should allow more comprehensive evaluation of swallowing disorders and provide more useful information for the therapeutic plan.

The preliminary data about pilot experiences in this field are reported below.

\section{Materials and methods}

Using a Storz endoscope with a reversible tip of $180^{\circ}$ (model 11101RP2, $30 \mathrm{~cm}$ long, $3.5 \mathrm{~mm}$ in diameter, tip mobility: up $180^{\circ}$, down $90^{\circ}$ ), starting from a position intermediate between high and low, it is possible to introduce the tip of the instrument into the back of the oral cavity (anterior position or retrograde position). From this position, it is possible to see an inverted image of the oral cavity and its content, up to the teeth and lips (Fig. 1a; in Fig. 1b the radiological visualisation of the endoscope in place).

In the experiences described, all evaluations were performed in the usual fashion scheduled in our institution ${ }^{89}$, completed with bolus tests and recorded with a workstation (Xion medical products GmbH, Berlin Buchholz). Regarding the tests with bolus, it should be specified that there is no general consensus regarding the specifics of the tests nor is there a validated procedure regarding the sequences of
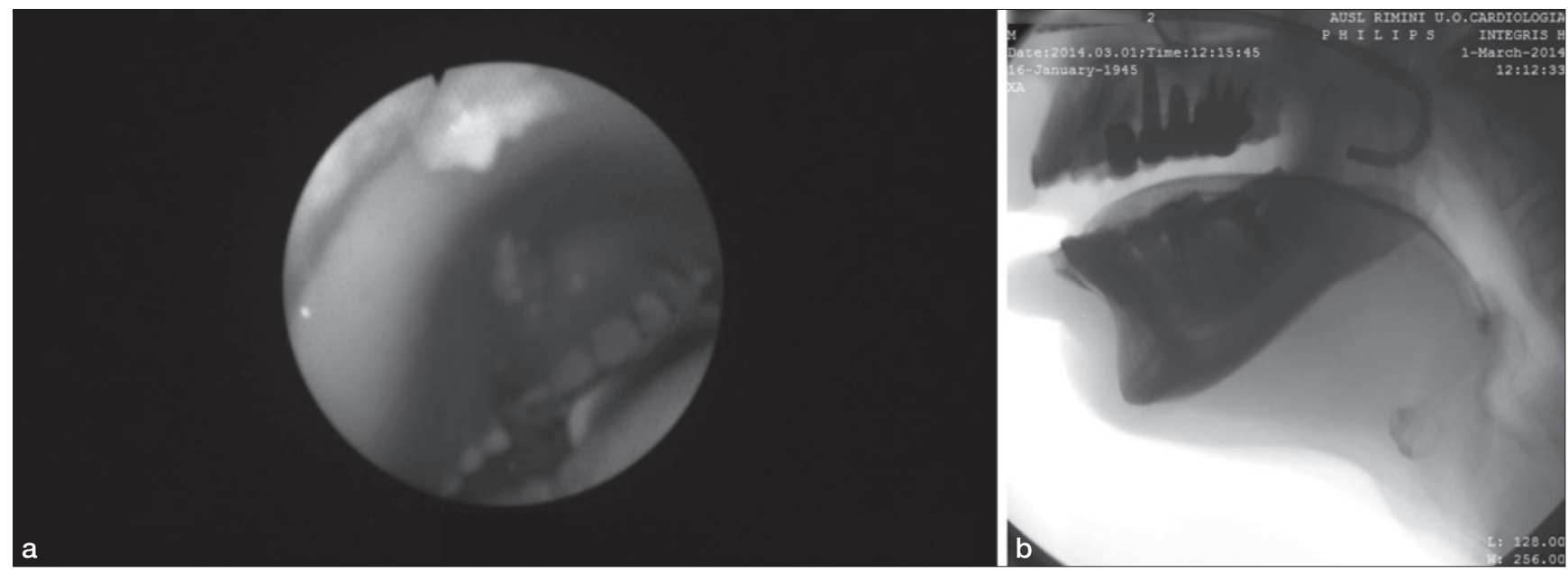

Fig. 1. a) Anterior or retrograde position: the oral cavity is directly visible; b) radiological lateral view. [The a) photographs have been rotated $180^{\circ}$ to obtain viewing equal to the real one and make the images more easily interpretable.]. 
consistencies, volumes and number of trials for each bolus ${ }^{8}$. An average of three boluses for each consistency has been proposed ${ }^{1-4}$, although it has been documented that in neurological and in post-surgical head and neck patients, 7 and 2 trials, respectively, are an adequate number to better document, with FEES, aspiration of thin liquids ${ }^{10}$.

\section{Tolerability analysis}

Both FEES and O-FEES were proposed respectively to a sample of 52 consecutive out-patients $(29 \mathrm{M} / 21 \mathrm{~F}$, mean age 66.96 yrs \pm 15.46 , range 22-88) (Table I) complaining of swallowing disorders of different aetiology seen in our swallowing centre from January to March 2014.

After the procedures, each patient was requested to complete a 10-point questionnaire for FEES and O-FEES. Pain, gagging, choking, anxiety and overall tolerability were measured on a 1 to 10 scale, with 1 being well-tolerated and 10 being poorly tolerated (Table II) ${ }^{11}$. Repeated measure analysis of variance (rm-ANOVA) model was used to test mean difference of tolerability in the same subjects after FEES and O-FEES. Cronbach's alpha reliability coefficient was calculated to assess the internal consistency of the tolerability questionnaire, with values above 0.7 indicating desirable levels ${ }^{12}$. Finally, an independent t-test was performed to compare the O-FEES tolerability score between males and females.

\section{Reliability \& validity analysis}

Eight consecutive male outpatients (mean age 76.00 years \pm 10.81 , range 56-89) were submitted to a simultaneous O-FEES and VFSS. Patients were complaining of swallowing disorders of different aetiology (Table III). O-FEES was performed with the instrumentation previously described and the endoscope in the anterior position. VFSS was performed with a Philips Poly Diagnostic $\mathrm{C}$ and recorded with a cardiac imaging digital recorder, $25 \mathrm{fps}$, with the samples being recorded on CD support. All patients were firstly submitted to VFSS to clarify the clinical complaint and the physiopathology of the swallowing disorder. Subsequently, they were submitted to simultaneous O-FEES and VFSS. Considering the aim of the study (identification of radiographic symptoms) and to reduce exposure to ionising radiation, during O-FEES it was decided to test only one bolus for each consistency. Thus, during O-FEES, and with the endoscope in place, one bolus of different consistency was given to each patient: creamy, solid and liquid (5 cc for creamy and liquid and $1 / 4$ of a cracker). Barium powder (Prontobario HD, Bario Solfato Ph.Eur. 98.45\% p/p, BRACCO S.p.A. Milan) was added to the foods and sprinkled on the surface of the crackers, without changing their consistency or palatability. The patients prepared the bolus and swallowed without any command. Some patients were not able to test all three consistencies, owing to the severity of their complaint.
Table I. Tolerability analysis: case series.

\begin{tabular}{clll}
$\begin{array}{c}\text { No. } \\
\text { pts }\end{array}$ & Main pathology & $\begin{array}{c}\text { Mean age (years) } \\
\text { Range: 22-88 yrs }\end{array}$ & Gender \\
5 & Dementia & & \\
3 & Radiotherapy sequelae & \\
1 & Myastenia gravis & \\
2 & Post-head and neck surgery & \\
7 & Parkinson's disease & \\
10 & Cerebrovascular disease sequelae & \\
1 & Multiple sclerosis & \\
2 & Steinert syndrome & \\
1 & Syringomyelia & \\
2 & Traumatic brain injury & \\
1 & Corea major & \\
7 & Internistic disease & \\
2 & Laryngeal paralysis & \\
6 & Oesophago-gastric disease & \\
2 & Failed 0-FEES (GERD, dementia) & \\
52 & TOTAL & \\
\hline
\end{tabular}

\section{Table II.}

\begin{tabular}{l} 
10-question assessment of procedure acceptability \\
(anxiety, pain, gagging, or choking with insertion of the endoscope \\
or during the procedure) \\
Items \\
\hline $\mathbf{1}$
\end{tabular}


Table III. Reliability \& Validity analysis: case series.

\begin{tabular}{llcc} 
Patient \# & Main pathology & Gender & Age \\
\hline 1 & Arnol-Chiari malformation & M & 56 \\
2 & MSA-P & M & 85 \\
3 & Myastenia gravis & M & 73 \\
4 & Vascular dementia & M & 74 \\
5 & Parkinson's disease & M & 75 \\
6 & Supraglottic laryngectomy & M & 85 \\
7 & Cervical hyperostosis & M & 89 \\
8 & Steinert syndrome & M & 71 \\
\hline
\end{tabular}

Table IV. VFSS parameters considered.

\begin{tabular}{l} 
Oral phase parameters \\
Preparation \\
\hline Cannot form a bolus \\
Cannot hold a bolus \\
Abnormal hold position \\
Propulsion \\
\hline Tongue moves forwards to start the swallow \\
Stasis of food on the tongue \\
Disturbed lingual peristalsis \\
Incomplete tongue to palatal contact \\
Adherence of food to the hard palate \\
Uncontrolled bolus or premature loss of food into the pharynx \\
Piecemeal deglutition
\end{tabular}

Table V. Differences among the pairs of answers of 10-question assessment of procedure acceptability ( $F=F E E S O F=0-F E E S)$.

\begin{tabular}{|c|c|c|c|c|c|c|}
\hline Questions & Obs & Mean & Std. Dev & Min & $\operatorname{Max}$ & $\begin{array}{r}\text { F-statistic } \\
p<0.01\end{array}$ \\
\hline $\mathrm{F} 1$ & 50 & 3.46 & 1.232386 & 1 & 8 & \multirow{2}{*}{0.000} \\
\hline OF1 & 50 & 5.06 & 1.300078 & 1 & 8 & \\
\hline F2 & 50 & 2.52 & 0.762380 & 2 & 5 & \multirow{2}{*}{0.000} \\
\hline OF2 & 50 & 3.86 & 1.178203 & 2 & 7 & \\
\hline F3 & 50 & 2.52 & 0.862838 & 1 & 5 & \multirow{2}{*}{0.000} \\
\hline OF3 & 50 & 5.54 & 1.631451 & 1 & 8 & \\
\hline F4 & 50 & 1.56 & 0.674915 & 1 & 4 & \multirow{2}{*}{0.000} \\
\hline OF4 & 50 & 4.0 & 1.498298 & 1 & 9 & \\
\hline F5 & 50 & 2.0 & 0.968904 & 0 & 5 & \multirow{2}{*}{0.000} \\
\hline OF5 & 50 & 4.82 & 1.637444 & 1 & 8 & \\
\hline F6 & 50 & 1.38 & 0.966584 & 0 & 6 & \multirow{2}{*}{0.000} \\
\hline OF6 & 50 & 3.6 & 1.678191 & 1 & 9 & \\
\hline F7 & 50 & 3.84 & 1.283490 & 0 & 6 & \multirow{2}{*}{0.000} \\
\hline OF7 & 50 & 5.5 & 1.488048 & 2 & 10 & \\
\hline F8 & 50 & 2.78 & 0.840068 & 2 & 5 & \multirow{2}{*}{0.000} \\
\hline OF8 & 50 & 4.54 & 1.541401 & 2 & 8 & \\
\hline F9 & 50 & 4.48 & 1.216217 & 2 & 7 & \multirow{2}{*}{0.0015} \\
\hline OF9 & 50 & 4.86 & 1.178203 & 2 & 8 & \\
\hline F10 & 50 & 3.28 & 0.729551 & 2 & 5 & \multirow{2}{*}{0.000} \\
\hline OF10 & 50 & 5.2 & 1.525297 & 2 & 9 & \\
\hline Total F & 50 & 27.82 & 6.76332 & 15 & 47 & \multirow{2}{*}{0.000} \\
\hline Total OF & 50 & 46.98 & 11.9223 & 15 & 77 & \\
\hline
\end{tabular}

For each patient, short videos were obtained for each oral transit. The videos, collected in pairs for each patient, were seen blindly by two raters.

According to Logemann ${ }^{13}$, 10 of 15 parameters (Table IV) were considered for each consistency tested (creamy, solid, liquid). Each rater scored every symptom for VFSS and O-FEES in a binary way, the parameter being present or absent (yes/no response where yes $=1$ and no $=0$ ). The scores, for each consistency, were globally considered in relation to the reduced sample. Thus, in this way, the OFEES and the VFSS scores were calculated as the sum of every score, realised for each symptom, and considered as a single ordinal number ranging from 0 to 10 (arithmetic mean \pm standard deviation). This final score expresses the severity of oral impairment of swallowing, stating the 19 symptoms. Timing was not considered.

Inter-rater agreement between the two judges for the O-FEES and VFSS scores was assessed with the single score intra-class correlation coefficient (ICC), which was interpreted as follows: 0-0.2, poor agreement; 0.3-0.4, fair agreement; 0.5-0.6, moderate agreement; 0.7-0.8, strong agreement; $>0.8$, almost perfect agreement. To validate O-FEES with VFSS (used as "gold standard") the BlandAltman test was used.

All statistical analyses were performed with SPSS 21 software.

All patients were over 18 years old and gave written consent to the procedures, according to the Declaration of Helsinki.

\section{Results}

Regarding the tolerability analysis, of the 52 participants who were enrolled in the study, $50(96 \%)$ completed both procedures: 2 patients discontinued O-FEES secondary to excessive gag. No participant experienced any adverse event or complication. The mean and standard deviation for each answer to the 10 questions are reported in Table V. The major differences between the pairs of answers was noted for answer 3 (gagging during insertion), answer 4 (gagging and retching during the procedure), answer 5 (choking during insertion) and answer 8 (anxiety during procedure). The difference between the means for overall tolerability (question 10) was 1.92. Differences between FEES answers and O-FEES answers for each question and among all the items considered overall were statistically significant (rm-ANOVA; F-statistic $\mathrm{p}<0.01$ ). For FEES and O-FEES answers, Cronbach's alpha reliability coefficient was, respectively, 0.88 (CI, 83-92) and 0.94 (CI, 91-96) and can be considered to be highly consistent. The total O-FESS tolerability score (mean males 45.6; mean females 47.7) did not document any difference between male and female, with a t-test $p$ value of 0.76 .

Considering the reliability and validity analysis, the interrater agreement concerning endoscopic and radiological 
evaluations between the two raters showed a good value of intra-class correlation coefficient considering the parameters evaluated by O-FEES and the parameters evaluated by VFSS. In the first case, the intra-class correlation coefficient (ICC) $(95 \%$ CI) was 0.875 (0.373-0.979), and in the second case it was 0.921 (0.542-0.986). The BlandAltman test showed a bias of -0.24 (95\% limits of agreement; -1.77 to +1.19 ), which suggests that both methods produced almost identical results.

\section{Discussion}

The events that occur in the oral cavity during mastication and propulsion are a complex sequence of neuro-muscular acts, linked with the pharyngeal bio-mechanical events that coordinate breathing and the passage of the bolus through the pharyngeal cavity. Mastication, in particular, requires the coordination of lips, cheeks, tongue, floor of mouth muscles and saliva to chew food until obtaining the bolus. VFSS is the best instrumental examination for a complete view of the oral phase of swallowing. Logeman ${ }^{13}$ listed the main topics to consider during evaluation and reporting of this phase.

O-FEES, a procedure conceived to directly view the oral cavity during swallowing, gives information about oral preparation and propulsion of the bolus, as well as residue after swallowing.

According to the experience reported, O-FEES, although accepted and safe, (only 2 of 52 patients did not tolerate it, without any complication during the study) seems to be more uncomfortable compared to FEES. Table V shows a large variability in the scores of the pairs of answers, which were all statistically significant. Insertion of the endoscope and feeling of gagging during the procedure seemed to be the major concerns of patients. The difference between the means for anxiety and overall tolerability was nonetheless quite low. In addition, the sum of the final total scores was significant. The overall tolerability of O-FEES is probably decreased if the oral cavity is smaller and more sensitive compared to the pharygeal cavity. Furthermore, with an equal volume and consistency of the bolus, the oral phase takes a comparably longer time to be concluded compared with the pharyngeal phase of swallowing: during this time, the contact of the endoscope with the mucosa may be perceived as disturbing by the patient, if not outright painful. Although the male's pharynx is larger than the females, gender differences in tolerability were not documented in our experience. Probably the relationship between FEES and O-FEES tolerability could be mainly influenced by individual anatomical variations (surface/volume) rather than variations due to gender. In addition, the dexterity of the clinician in carrying out such a delicate procedure must be taken into account. Regarding comparison with the gold standard, it was decided to consider a simple rate expressing the status for each parameter (radiographical symptom) selected by Logeman ${ }^{13}$ to be present or absent (yes/no response). No other diagnostic considerations about preparation, propulsion and timing were made, considering that at this stage, in this preliminary study, only the ability of O-FEES to evaluate oral events (yes/no events) was tested, without any other more sophisticated considerations.

With these premises, it can be noted that the agreement between the scores attributed by the two raters to both O-FEES and VFSS was strong, and the results of O-FEES and VFSS scores are correlated to each other, that is $\mathrm{O}$ FEES can be considered valid compared with the radiological gold standard relatively to the parameters selected. It can be disputed that only approximate radiological parameters have been considered, despite the complexity of the oral phase: this is true but the research, at this stage, does not allow further detailed considerations.

\section{Conclusions}

A new procedure to directly evaluate the oral phase of swallowing with endoscopes has been proposed. The procedure is a variation of FEES and has been called oralFEES (O-FEES). The procedure is feasible without any further technological implementation, but only by reversing the tip of the endoscope back in the oral cavity or just behind the soft palate. In this way, the anatomical boundaries of the oral cavity and all the events that occur inside the cavity (mainly the tongue movements as in verbal articulation, maneuvers, mastication, bolus formation) are visible. Considerations can also be made about the efficiency of the oral phase, evaluating the residues after swallowing.

Compared with the radiological gold standard, O-FEES offers reliable information about oral preparation (bolus formation, holding the bolus, abnormal bolus position) and oral propulsion (residues, disturbed lingual peristalsis, incomplete lingual contact, piecemeal deglutition, spillage). For these reasons, O-FEES may offer further clinical information for evaluation of patients with conditions that considerably alter the oral phase of swallowing, such as ALS, Parkinson, chorea, ictus acute/sequelae, radiotherapy: in general, conditions affecting the muscular activities in terms of speed, range of motion, precision and symmetry. Additionally, anatomo-functional alterations due to malformations or surgery sequelae of the lips, tongue, gums and palate, for example, might be directly evaluated. Bearing in mind the previous considerations about the volume and sensation of the surfaces, O-FEES seems to be unsuitable for use in children or in other uncooperative patients, unless otherwise proven by a simple attempt.

In clinical practice and compared with FEES, O-FEES is a feasible and safe procedure. During O-FEES, patients experienced higher levels of pain, gagging, choking and anxiety, although the procedure was accepted and well 
tolerated. Differences in tolerance may be due, among other factors, to a lack of dexterity on the part of the clinician in performing the procedure.

Attempts are in progress to routinely use O-FEES in clinical practice by involving patients with different aetiologies.

\section{References}

1 Langmore SE, Schatz K, Olsen N. Fiberoptic endoscopic examination of swallowing safety: a new procedure. Dysphagia 1988;2:216-9.

2 Bastian RW. Videoendoscopic evaluation of patients with dyaphagia: an adjunct to the modified barium swallow. Otolaryngol Head Neck Surg 1991;104:339-50.

3 Leder SB, Sasaki CT, Burrel MI. Fiberoptic endoscopic evaluation of dysphagia to identify silent aspiration. Dysphagia 1998;13:19-21.

4 Langmore SE. Endoscopic evaluation of oral and pharyngeal phases of swallowing. GI Motility online (2006).

5 Smith CH, Logemann JA, Colangelo L, et al. Incidence and patient characteristics associated with silent aspiration in the acute care setting. Dysphagia 1999;14:1-7.
6 Kelly AM, Drinnan MJ, Leslie P. Assessing penetration and aspiration: how do videofluoroscopy and fiberoptic endoscopic evaluation of swallowing compare? Laryngoscope 2007;117:1723-7.

7 Logemann JA. Evaluation and treatment of swallowing disorders. Second edition. Austin, Texas: Pro.ed; 1998.

8 Farneti D. The instrumental gold standard: FEES. Journal of GHA 2014;3:1055-60.

9 Farneti D. Valutazione videoendoscopica. In Schindler O, Ruoppolo G, Schindler A, editors. Deglutologia. Torino: Omega Edizioni; 2001. p. 167.

10 Baijens LW, Speyer R, Pilz W, et al. FEES protocol derived estimates of sensitivity: aspiration in dysphagic patients. Dysphagia 2014;29:583-90.

11. Peery AF, Hoppo T, Garman KS, et al. Feasibility, safety, acceptability, and yield of office-based, screening transnasal esophagoscopy (with video). Gastrointest Endosc 2012;75:945-53.

12 Cronbach LJ. Coefficient alpha and the internal structure of tests. Psychometrika 1951;16:297-334.

13 Logemann JA. Manual for the video-fluorographic study of swallowing. Austin, Texas: Pro-ed; 1986. 